\title{
The Effects of Night Shift Work on the Psychosocial Status of Nurses in Akre City Hospitals
}

\author{
Mohammed Haider Musa* \\ Zekri Mahmood Merza***
}

\begin{abstract}
Background and aim: Over the last several decades, there has been a rapid increase in the number of shift workers worldwide. In general, the shift has been divided to the day and night shifts. Nurses working the night shift have been found to experience physiological, social, and psychological problems. General purpose of this study is to identify the effects of night shift on nurses.

Materials and method: A descriptive study conducted on nurses working in Akre governmental hospitals to identify sources of the effects of night shift work on nurses. The study included (76) samples of nurses from the period 30th February to 2nd April 2016.
\end{abstract}

Results: The results of the study have shown that there are real problems in all areas; psychospcial problems come first in rank.

Conclusion: The study also revealed that there are significances between night shift work and variables of (sex, years of experience, married status).

Keywords: Effect, Night shift, Social problems, Psychological problems.

INTRODUCTION people within each country (Brown-DeGgne and

The terms shift work and night shift is not a modern phenomenon. During the civilization development, man has lived and worked following his activity cyclic changes of day and night (Aranđelović et. al., 2009; Harrington, 2001). Over the last several decades, there has been a rapid increase in the number of shift workers worldwide (Sudo and Ohtsuka, 2001). A cording to the ILO (1994), working in shifts is "a method of organization of working time in which workers succeed one another in the workplace so that the establishment can operate longer than the hours of work of individual workers" at a different day and night hours.

Shift work is an employment practice designed to make use of, or provide service across, all 24 hours of the clock each day of the week (often abbreviated as 24/7). The practice typically sees the day divided into shifts, set periods of time during which different groups of workers perform their duties. The term "shift work" includes both long-term night shifts and work schedules in which employees change or rotate shifts (Sloan Work and Family Research, 2014; Institute for Work and Health)

The health service is one of the industries that provide a continuous service around the clock, for the benefit of all citizens in any country. Health service personnel are responsible for the provision of health care through the application of medical science knowledge, skill and expertise in meeting the health needs of all

Eskes, 1998).

Nurses working the night shift have been found to experience physiological difficulties and sleep related issues (Shandor, 2012). Associated problems that arise outside of work include drowsy driving, family/child care difficulties, and less leisure time (Kunert et. al., 2007; Fujimoto et. al., 2008; Bonet-Porqueras et. al., 2009). Shift work of nurses is one of the critical issues in hospital inpatient care, making it vitally important to understand the functioning and efficiency of health care and its impact on the health of employees (Harrington, 2001). The general purpose of this study is to identify the effects of night shift on nurses. This type of investigation is very useful to hospital administrators, because it helps in improving all nursing management processes and to protect nurses from these adverse effects. The specific objectives of this study are to identify the relationship between socio demographic characteristics of the nurses and effects of night shift, and to reveal the essential sources of effects of night shift among nurses.

\section{MATERIALS AND METHOD}

A descriptive design was carried out throughout the present study from the period 30th February to 2nd April 2016 in order to achieve the objectives of the study. The study was carried out among nurses working in Akre Governmental hospitals .Seventy six nurses working in two Governmental hospitals, Gulan hospital, and

\footnotetext{
* Lecturer / Radiology Department/ Duhok Technical Institute .

** Assistant Lecturer / Nursing Department/Duhok Technical Institute .

*** Assistant Lecturer / Nursing Department/ Akre Technical Institute.
} 
Emergency hospital constituted the sample used for the study. The exclusion criteria are to be a head nurse or supervisor, working in the same area. Study tool "questionnaire" was validated by a number of referees and based on literature review when developed by the researcher to ensure cultural and language appropriateness. After the arrangement of information obtained from referees, the tools of the study consisted of two parts:

Part1: Included the independent variables like, sex, marital status, level of education, years of service.

Part2:The researcher arranges the questionnaire by depending on a five Liker scale ranging from 1 (strongly disagreement) to5 (strongly agreement), In order to knowledge the importance of each paragraph and the importance of the total score after getting on the standard deviation and percentages, the questionnaire was divided into two areas, psychological effects and social effects.

The questionnaire was administrated to (11) nurses, (6) nurses in Gulan hospital, (5) nurses in Emergency hospital, after a period of (14) days, the same questionnaire was administrated to the same group to find out the correlation between the scores of pre and post test. Pearson's Coefficient Correlation was used. The results were $(\mathrm{r}=0.76)$ were significant at $(\mathrm{p}$. $<0.01$ ). Table (1).

\section{Statistical analysis:}

1- Percentages were used to calculate the description of the sample.

2- Mean, standard deviation and percentage were used to estimate the items of the data.

3- t-test for independent sample was used to determine the differences between males and females.

4-Analysis of variance, one way (ANOVA) was used to determine the differences between the scores of problems and variables.

\section{Results}

\section{Figure (1): Level of source of problems}

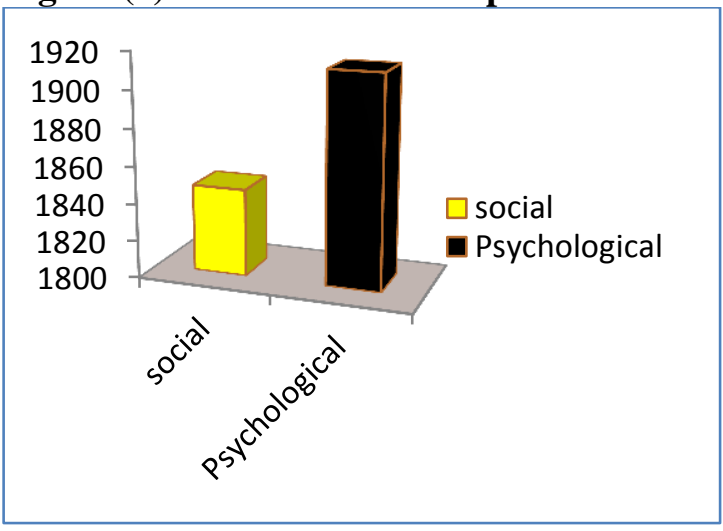

Table (1): Shows the scores of test and retest for defining the reliability of the questionnaire

\begin{tabular}{|c|c|c|}
\hline \multirow{2}{*}{ No. } & \multicolumn{2}{|c|}{ Questionnaire } \\
\cline { 2 - 3 } & Test & Re-test \\
\hline 1 & 28 & 26 \\
\hline 2 & 23 & 24 \\
\hline 3 & 25 & 23 \\
\hline 4 & 19 & 21 \\
\hline 5 & 25 & 23 \\
\hline 6 & 27 & 25 \\
\hline 7 & 22 & 23 \\
\hline 8 & 26 & 22 \\
\hline 9 & 21 & 23 \\
\hline 10 & 18 & 19 \\
\hline 11 & 24 & 21 \\
\hline
\end{tabular}

Table (2): Socio-demographic characteristics of the nurse's staff

\begin{tabular}{||l|c|c||}
\hline Characteristics & F & \% \\
\hline Age & 51 & 67.1 \\
\hline less than 30 & 23 & 30.3 \\
\hline From 30-40 years & 2 & 2.6 \\
\hline More than 40 years & 76 & 100.0 \\
\hline Total \\
\hline Gender \\
\hline Male \\
\hline Female \\
\hline Total & 41 & 53.9 \\
\hline Level of Education & 35 & 46.1 \\
\hline Less than diploma & 76 & 100.0 \\
\hline Diploma & 18 & 23.7 \\
\hline Collage & 46 & 60.5 \\
\hline Total & 12 & 15.8 \\
\hline Marital Status & 76 & 100.0 \\
\hline Single & 24 & 31.6 \\
\hline Married & 50 & 65.8 \\
\hline discovered & 2 & 2.6 \\
\hline Total & 76 & 100.0 \\
\hline
\end{tabular}

Table (3): Percentage distribution of services years

\begin{tabular}{|l|c|c|}
\hline Years & F & \% \\
\hline 1 years & 28 & 36.8 \\
\hline 2 years & 26 & 34.2 \\
\hline 3 years & 15 & 19.7 \\
\hline 4 years & 7 & 9.3 \\
\hline Total & 76 & 100.0 \\
\hline
\end{tabular}


Table (4): Comparison between the scores of problems with regard to the Level of education

\begin{tabular}{|c|c|c|c|c|c|c|}
\hline Variable & S.O.V & S.S & df & M.S & F-value & P-value \\
\hline \multirow{3}{*}{ Social } & Between Groups & 67.818 & 2 & 33.909 & \multirow{3}{*}{1.046} & \multirow{3}{*}{0.05} \\
\hline & Within Groups & 2366.221 & 73 & 32.414 & & \\
\hline & Total & 2434.039 & 75 & & & \\
\hline \multirow{3}{*}{ Psychological } & Between Groups & 101.614 & 2 & 50.807 & \multirow{3}{*}{1.909} & \multirow{3}{*}{0.05} \\
\hline & Within Groups & 1943.162 & 73 & 26.619 & & \\
\hline & Total & 2044.776 & 75 & & & \\
\hline
\end{tabular}

Table (5): Comparison between the scores of problems with regard to the Experience years

\begin{tabular}{||l|l|c|c|c|c|c||}
\hline Variable & \multicolumn{1}{|c|}{ S.O.V } & S.S & df & M.S & M.S & F-value \\
\hline \multirow{3}{*}{ Social } & Between Groups & 256.367 & 3 & 85.456 & \multirow{3}{*}{2.825} & \multirow{2}{*}{0.05} \\
\cline { 2 - 5 } & Within Groups & 2177.672 & 72 & 30.245 & & \\
\cline { 2 - 7 } & Total & 2434.039 & 75 & & & \multirow{3}{*}{0.05} \\
\hline \multirow{3}{*}{ Psychological } & Between Groups & 248.844 & 3 & 82.948 & & \\
\cline { 2 - 5 } & Within Groups & 1795.932 & 72 & 24.944 & & \\
\cline { 2 - 5 } & Total & 2044.776 & 75 & & & \\
\hline
\end{tabular}

Table (6): Comparison between the scores of problems with regard to the Marital Status

\begin{tabular}{||l|l|c|c|c|c|c||}
\hline Variable & \multicolumn{1}{|c|}{ S.O.V } & S.S & df & M.S & M.S & F-value \\
\hline \multirow{3}{*}{ Social } & Between Groups & 380.822 & 2 & 190.411 & \multirow{3}{*}{6.687} & \multirow{2}{*}{0.05} \\
\cline { 2 - 6 } & Within Groups & 2050.298 & 72 & 28.476 & & \\
\cline { 2 - 6 } & Total & 2431.120 & 74 & & & \multirow{2}{*}{0.05} \\
\hline \multirow{3}{*}{ Psychological } & Between Groups & 243.797 & 2 & 121.898 & \\
\cline { 2 - 5 } & Within Groups & 1796.203 & 72 & 24.947 & & \\
\cline { 2 - 5 } & Total & 2040.000 & 74 & & & \\
\hline
\end{tabular}

Table (7): Comparison between the scores of problems with regard to the sex

\begin{tabular}{||c|l|c|c|c|c|c||}
\hline \multicolumn{1}{|c|}{ Variable } & Group & Number & M.S & S.D & t-value & P-value \\
\hline \multirow{2}{*}{ Social problems } & Male & 41 & 25.4878 & 5.5683 & \multirow{2}{*}{2.002} & \multirow{2}{*}{0.05} \\
& Female & 35 & 22.9143 & 5.6065 & & \multirow{2}{*}{0.05} \\
\hline \multirow{2}{*}{ Psychological problems } & Male & 41 & 26.2683 & 4.41035 & \multirow{2}{*}{2.023} & \\
& Female & 35 & 23.8857 & 5.83988 & & \\
\hline
\end{tabular}

\section{DISCUSSION}

Shift works effect social and family relationships, by disrupting the worker's daily pattern of work. The nurses reported difficulties in meeting family responsibilities and attending social functions, getting sufficient sleep, and a lack of family cooperation (Soares et. al., 2012).

There has been a scarcity of studies on the impact of shift work on mental health. Studies have found an association between shift work and general mental health (Suzuki et. al., 2004; Poole et. al., 1992).

\section{Psychosocial problems}

It is important to note that even though nurses make a request to work on a night shift, they still regard it as being strenuous.

The result of our study shows that there are real psychological problems in the nurse from the nurse's point of view (83.9\%) (Figure 1). This result is an agreement with (Doli Deori, 2012), which show in his study the concentration as one of the psychological concepts of night shift, $28 \%$ of respondent felt that their concentration is low, $64 \%$ felt that their concentration is normal, and $8 \%$ felt that is almost high even on the night shift.

\section{Social problems}

Night shift causes an imbalance between desired lifestyle and

Work shift. The study revealed that there are social problems among nurses (81\%) (Figure 1). This result is an agreement with the result of (Doli Deori, 2012), which indicates that the 93\% of the nurses were affected and 7\% not affected their social life. Also This result is an agreement with the result of (Isah EC et. al., 2008), which reported that $205(66.1 \%)$ night duty nurses 
complained of negative impact on social and family life.

\section{Study of variables}

In order to know whether there are effects of the socio-demographic characteristics of the nurses on the occurrence of problems, the researcher categorized the sample of the study into many groups according to certain variables.

Table (4) indicates that there are no significant differences in night shift among nurses with regard to the level of education at $(\mathrm{p}<0.01)$.This result is an agreement with (Reynolds, 1997; Chapman, 1995), which indicates that there are no significant differences among nurses with regard to the level of education , and disagreement with Noori AkhtarDanesh (2007), which shows that there are significant association between the level of education and depression.

It appears from the table (5) that there are significant differences in night shift among nurses with regard to the years of experience at $(p<0.01)$. The researcher attributed the cause to the small number of training courses for nurses. This result is an agreement with the results of (Chapman, 1995), which indicate that there were no significant differences in night shift among nurses with regard to the years of experience.

With regard to married status, it was revealed that there were significant differences among nurses at $(p<0.01)$ (table 6). This result is an agreement with the results of (Harrington, 2001), which indicates the marital responsibilities can be severely disrupted by shift work or long hours. Childcare, housework, shopping, and leaving a partner alone at night can all lead to marital strain and family dysfunction, also this result is an agreement with the results of (Noori Akhtar, 2007), which indicates the relation between depression and marital status is highly significant.

The study revealed that there are significant differences in night shift among nurses with regard to the sex of the nurses at $(p<0.01)$ (table 7) the researcher attributed the cause to the evening shifts uniforms for all nurses, regardless of gender. This result is disagreement with the result of (Yehia, 2003), which indicates that the female nurses were more exposed to psychosocial problems.

\section{CONCLUSIONS}

According to the objectives of the present study and the results of the data analysis, the following conclusions have been inferred There are tangible disorders in all (psychological and social) aspects according to the opinion of the nurses whereas the psychological aspect comes first in rank. There were no statistically significant differences, from the nurse's point of view, between the occurrence of problems and some variables like (sex, marriage status and years of experience). Finally, there were no statistically significant differences, from the nurse's point of view, according to the level of education.

\section{REFERENCES}

Aranđelović, M.; Jovanović, J. (2009). Medicina rada. Niš: Medicinski fakultet. http://www.medradanis.rs/docs/knjiga medicinarada.pdf

Bonet-Porqueras, R.; Moline-Pallares, A.; OlonaCabases, M.; et. al. (2009). The night shift: a risk factor for health and quality of life in nursing staff. Enfermeria Clinica. 19(2). P.p.76-82. PMid:19375656.

Brown-DeGgne, A. M.; and Eskes, G. A. (1998). Turning body times to shift time. Health Sciences Centre. 94 (98). P.p. 51-52.

Chapman, J. (1995): Collegial support linked to reduction of job stress. Nursing management. 24(5). P.p.52.

Doli, Deori. (July-August, 2012).The experience of night shift registered nurses in an acute care setting: a phenomenological study. International Journal of Latest Research in Science and Technology.1 (2). P.p.D201D204.

Fujimoto, T.; Kotani, S.; Suzuki, B. (2008). Work-family conflict of nurses in Japan. Journal of Clinical Nursing.17(24): 32863295.

Harrington, J M. (2001). Health effects of shift work and extended hours of work. Occup Environ Med. 58. P.p.68- 72.

ILO: Asian tripartite workshop on working time arrangements: Proceedings, document no. PIACT/1994/2 (Geneva, 1994).

Isah, EC.; Iyama, CA.; Imoudu, GO. (2008). Health effects of night shift duty on nursing in a university teaching hospital in Benin City, Nigeria. Niger J Clin Pract. 2. P.p.144-148.

Institute for Work and Health, Ontario, Canada. "Fact Sheet, Shiftwork" (PDF). Retrieved 2014-09-25. Outside regular daytime hours (i.e., between approximately 0700 and 1800 Monday through Friday).

U.S. Congress. (1991). Office of Technology Assessment. "Biological Rhythms: 
Implications for the Worker. New Developments in Neuroscience".

Kunert, K.; King, M.; Kolkhorst; F. (2007). Fatigue and sleep quality in nurses. Journal of Psychosocial Nursing and Mental Health Services. 45 (8). P.p.30-37. PMid:17848042

Noori, Akhtar-Danesh; and Janet, Landeen. (2007). International Journal of Mental Health Systems. 1. $\quad$ P.p.4. doi:10.1186/1752-4458-1-4.

Poole, CJM.; Evans, GR.; Spurgeon, A.; Bridges, KW. (1992). Effects of a change in shift work on health. Occup Med. 42. P.p.93-9.

Reynolds, R. (1997). Self concept as a predictor of psychosocial stress in male and female nurses. Dissertation Abstract InternationalB. 57. P.p. 4763.

Shandor, AM. (2012). The health impacts of nursing shift work [dissertation]. Minnesota State University. P.p.100.
Sloan Work and Family Research, Boston College. "Shift work, Definition(s) of". Retrieved 2014-09-25.

Soares, M.; Jacobs, K.; Rathore, HH.; et. al. (2012). Shift work-problems-its impact on female nurses in Udaipur, Rajasthan, India. Work. 41. P.p.4302-4314.

Sudo, N.; and Ohtsuka, R. (2001). Nutrient intake among female shift workers in a computer factory in Japan. International Journal of Food Sciences and Nutrition. 52(4).P.p.367 378.

Suzuki, K.; Ohida,T.; Kaneita, Y.; Yokoyama, E.; Miyake, T.; Harano, S.; et. al. (2004). Mental health status, shift work, and occupational accidents among hospital nurses in Japan. J Occup Health.46(6). P.p.448-54. 